Massive hiatal hernia can present with symptoms or signs of cardiovascular or respira-

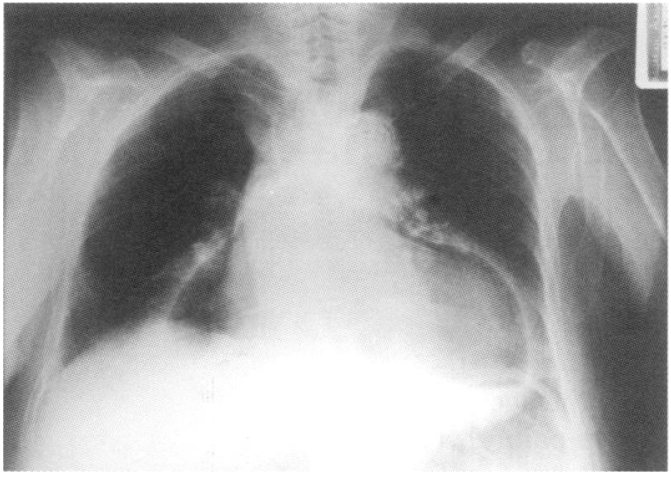

Figure 1 Chest radiograph on admission. tory dysfunction and can constitute a radiological differential diagnostic problem.

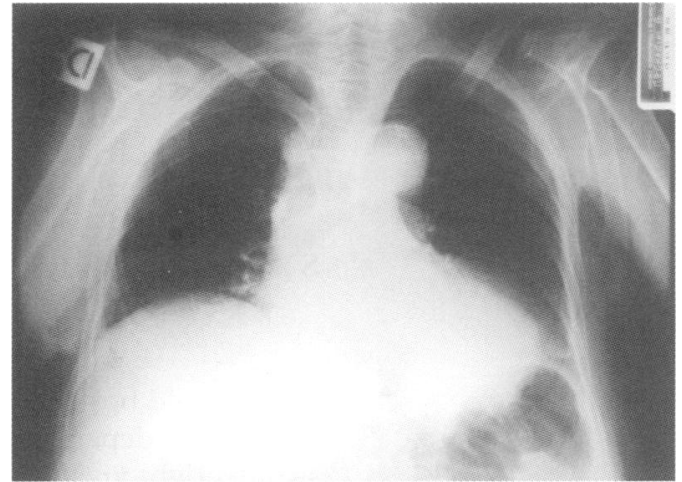

Figure 2 Chest radiograph after aspiration of fluid and air.

\title{
Retroperitoneal abscess presenting with a buttock swelling and anaemia
}

\author{
R L Spedding, I K Walsh
}

Belfast City Hospital, Belfast: Accident and Emergency

Department

R L Spedding

Department of

Urology

I K Walsh

Correspondence to: Dr Ruth Spedding, Consultant in Accident and Emergency, Warrington Hospital, Lovely Lane, Warrington, Cheshire WA5 1QC

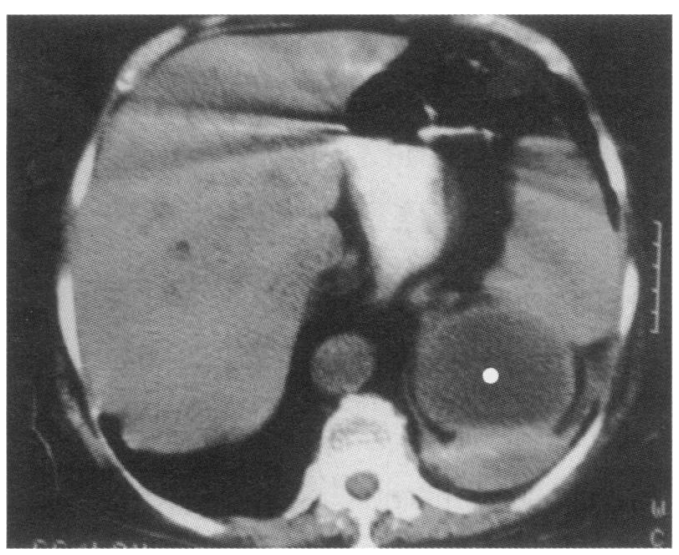

Figure 1 Left hydronephrotic kidney and retroperitoneal abscess (white dot in the hydronephrosis).

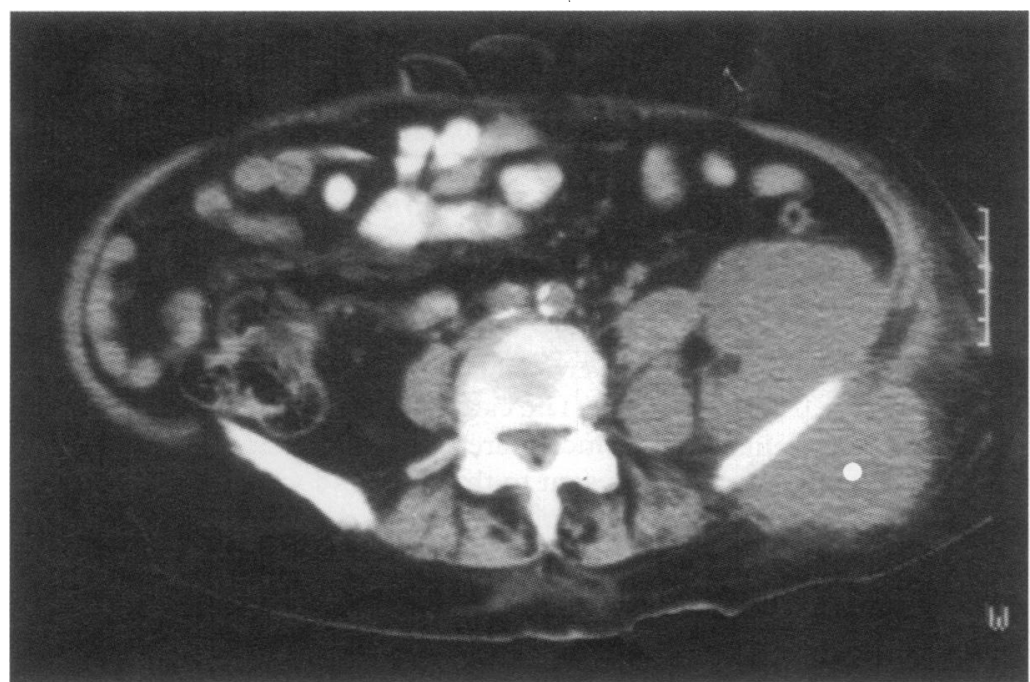

Figure 2 Retroperitoneal abscess in communication with the left buttock (white dot in buttock abscess).

A 68 year old woman presented to the accident and emergency department with nausea, anorexia, night sweats, and weight loss of 3.5 stone. She had an 18 year history of a staghorn calculus in a non-functioning left kidney. She had a tense, tender $6 \times 4 \mathrm{~cm}$ swelling over her left buttock with a balottable left kidney. She was apyrexic. Urinalysis was normal. Her erythrocyte sedimentation rate (ESR) was raised at $130 \mathrm{~mm} /$ hour as was the $C$ reactive protein at $116 \mathrm{mg} / 1$ (normal <20). She had a normochromic anaemia, with a moderate leucocytosis and a thrombocytosis. Computed tomography showed a hydronephrotic left kidney (fig 1) with a retroperitoneal abscess involving the psoas and quadratus lumborum muscles extending into the left buttock (fig 2). A total of $700 \mathrm{ml}$ of pus was drained. A nephrectomy was performed one month later.

Retroperitoneal abscess is not common. Most arise from the gastrointestinal tract. ${ }^{1}$ Pyonephrosis with a psoas abscess is rare. Patients may have a prolonged history of urinary tract infection, staghorn renal calculi, or hydronephrosis. ${ }^{2}$ Symptoms may be subtle and include dysuria, vomiting, pyrexia, loin pain, and weight loss. The classical signs of a loin bulge and hip flexion are unusual. ${ }^{1}$ Urinalysis may be negative. ${ }^{3}$ The combination of a raised ESR $>100 \mathrm{~mm} /$ hour and raised C reactive protein differentiate with a $100 \%$ sensitivity between a hydronephrotic and a pyonephrotic kidney. ${ }^{4}$ The anaemia of chronic disease may be an additional pointer. ${ }^{25}$

Ultrasound has a limited ability to demonstrate an infected hydronephrosis or small abscess. ${ }^{5}$ High resolution computed tomography has enabled the three compartments of the 
retroperitoneal space-the perirenal and the anterior and the posterior pararenal- to be further delineated. ${ }^{6}$ The posterior renal fascia had been thought to insert into the anterior portion of the psoas. It is now recognised that insertion is more commonly into the posterior psoas or the quadratus lumborum muscles, explaining the buttock mass in this case.
1 Procaccino JA, Lavery IC, Fazio VW, et al. Psoas abscess: difficulties encountered. Dis Colon Rectum 1991;9:784-9.

Watt I, Roylance J. Pyonephrosis. Clin Radiol 1975;4:513-19.

Watt I, Roylance J. Pyonephrosis. Chin Radiol 1975;4:513-19. Dis 1969;120:27-46.

$4 \mathrm{Wu}$ TT, Lee YH, Tzeng WS, et al. The role of C-reactive protein in the diagnosis of infected hydronephrosis and pyonephrosis. F Urol 1994;152:26-8.

5 Jeffrey RB, Laing FC, Wing VW, et al. Sensitivity of sonography in pyonephrosis: a revaluation. $A f R$ 1984;144:71-3

6 Korobkin M, Silverman PM, Quint LE, et al. CT of the extraperitoneal space: normal anatomy and fluid collections. $A f R$ 1992;159:933-4.

\title{
Persistent "haematoma"
}

\author{
Michael J Clancy
}

Emergency

Department,

Southampton General

Hospital, Tremona

Road, Southampton

SO16 6YD

Correspondence to:

Mr Clancy, Consultant.
A 71 year old women noticed a persistent swelling over her right tibial tuberosity after a blow to that area some 10 weeks earlier. Attempted aspiration by her general practitioner was unsuccessful and she was referred to her local accident and emergency (A\&E) department for further aspiration of the "haematoma". On examination there was a $6 \mathrm{~cm}$ fluctuant swelling from which no blood could be aspirated. Under local anaesthesia the lesion was incised, "loculi broken down and $50-70 \mathrm{ml}$ of blood expelled". The wound was closed and on review two weeks later the swelling appeared to be resolving.

The patient represented 10 weeks later with a recurrence of the swelling and underwent an ultrasound examination that showed a solid, highly vascular, well defined oval shaped mass in the subcutaneous tissue immediately over the tibial periosteum but with no evidence of local invasion. This was confirmed by magnetic resonance imaging (fig 1 ).

The patient had the lesion completely excised. Histologically the tumour was unusual and thought to be a pleomorphic hyalinising angectatic tumour of soft parts, which has only recently been described. ${ }^{1}$ There is a risk of local recurrence with this tumour type, which

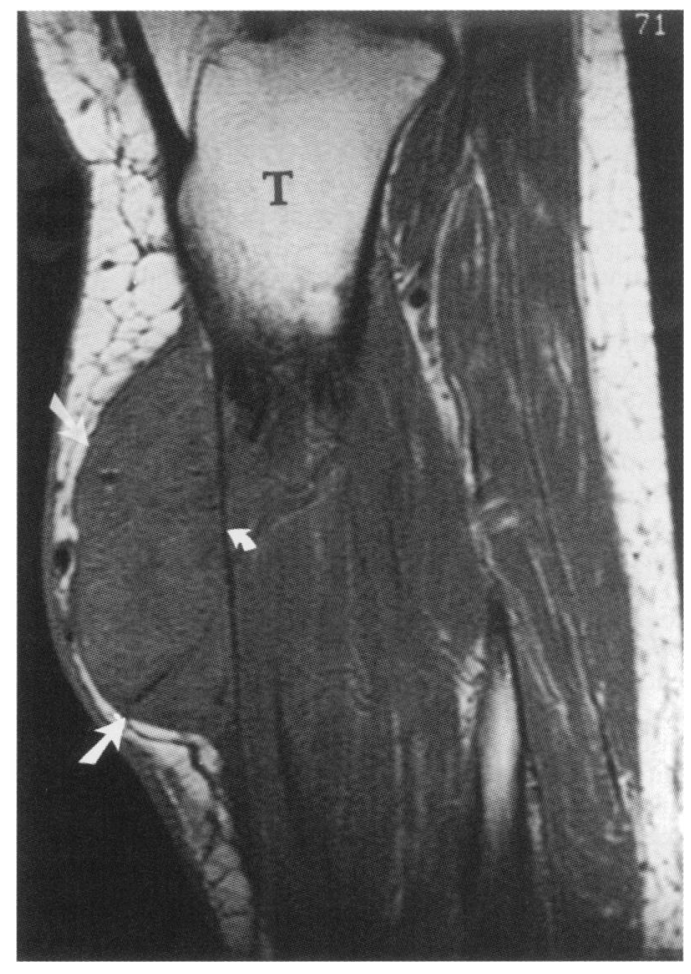

Figure 1 The sagittal T1 weighted magnetic resonance image through the lower leg showing a $6 \mathrm{~cm}$ well defined mass (larger white arrow) which is sitting on top of the apparently uninvolved fascia (smaller curved white arrow); sarcoma.

Soft tissue tumours presenting to $A \& E$ departments are likely to be rare and the diagnosis delayed. ${ }^{2}$ Persistence and the recurrence of the swelling point to this lesion not being a simple haematoma.

1 Smith ME, Fisher C, Wiess SW. Pleomorphic hyalinizing angiectatic tumour of soft parts. A low grade neoplasm resembling neurilemona. Am $\mathcal{F}$ Surg Pathol 1996;20:21-9.

2 McGovern SJ. Lumps, bumps, and soft tissue sarcomas. $\mathcal{f}$ Accid Emerg Med 1996;13:141-2.- 